\title{
MD Simulations of Microstructure Evolution During High-Velocity Sliding Between Crystalline Materials
}

\author{
Hong Jin Kim • Woo Kyun Kim • Michael L. Falk • \\ David A. Rigney
}

Published online: 4 June 2008

(C) Springer Science+Business Media, LLC 2008

\section{Erratum to: Tribol Lett (2007) 28(3):299-306 \\ DOI 10.1007/s11249-007-9273-2}

Following are corrections to the original article:

On p. 300, in the caption to Figure 2, 0.219 should be replaced by 1.461 .

On p. 301, line 12, 0.01 should be replaced by 0.033 .

On p. 301, line $33,0.15$ should be replaced by 0.074 .
On p. 301, in line 2 of Results and Discussion, 0.219 should be replaced by 1.461 .

On p. 302, in the caption to Figure 4, 0.219 should be replaced by 1.461 .

On p. 302, line 7, $\mathrm{s}^{2}$ should be replaced by $\sigma^{2}$.

These corrections do not affect the results and conclusions given in the paper.

The online version of the original article can be found under doi: 10.1007/s11249-007-9273-2.

H. J. Kim · D. A. Rigney $(\bowtie)$

Materials Science and Engineering, The Ohio State University, Columbus, OH 43210, USA

e-mail: rigney.1@osu.edu

H. J. Kim

Process Development Team, Memory Division, Semiconductor Business, Samsung Electronics, Hwasung-City, Gyeonggi-Do 445-701, Korea

W. K. Kim

Mechanical Engineering, University of Michigan, Ann Arbor, MI 48109, USA

M. L. Falk

Materials Science and Engineering, University of Michigan,

Ann Arbor, MI 48109, USA 